\title{
Hypothermic in situ perfusion of the porcine liver using Celsior or Ringer-lactate solution
}

\author{
S. Dinant • H. J. Roseboom • M. Levi • \\ A. K. van Vliet • T. M. van Gulik
}

Received: 25 February 2007 / Accepted: 20 December 2007 / Published online: 20 March 2008

(C) The Author(s) 2008

\begin{abstract}
Background Hypothermic perfusion (HP) of the liver is applied during total vascular exclusion (TVE) to reduce ischemic injury during liver resection. No studies have been performed comparing different perfusion solutions for HP. The aim of this experimental study was to compare Ringerlactate solution (RL) with Celsior solution (Cs) for HP in a pig model of 60-min TVE.

Method Twenty pigs underwent 60-min TVE of the liver. Groups were TVE without HP (no-HP, $n=9$ ), TVE with HP using RL $(n=6)$, and TVE with HP using Cs $(n=5)$. Blood and liver tissue samples were taken before TVE and during 24-h reperfusion.

Results In the no-HP group, plasma aspartate aminotransferase values were significantly increased during reperfusion $(p<0.05)$, while liver tissue $\mathrm{pO}_{2}$ levels $(p<$ 0.01 ) were decreased when compared to the HP groups. After 24-h reperfusion, bile production and liver tissue glutathione content were significantly higher $(p<0.05)$ in the Cs group $(42.0 \pm 1.7 \mathrm{~mL} / \mathrm{h}$ and $44.9 \pm 2.2 \mathrm{nmol} / \mathrm{mg}$, respectively) as compared to the RL group $(31.5 \pm 3.5 \mathrm{~mL} / \mathrm{h}$ and $19.6 \pm 1.8 \mathrm{nmol} / \mathrm{mg}$, respectively).
\end{abstract}

S. Dinant $\cdot$ H. J. Roseboom • A. K. van Vliet · T. M. van Gulik Department of Surgery, Surgical Laboratory,

Academic Medical Center,

Amsterdam, The Netherlands

M. Levi

Department of Internal Medicine,

Academic Medical Center,

Amsterdam, The Netherlands

S. Dinant $(\bowtie)$

Academic Medical Center,

Meibergdreef 9,

1105 AZ Amsterdam, The Netherlands

e-mail:s_dinant@hotmail.com
Conclusion The protective effect of HP during TVE was confirmed in this study. HP with Cs was more effective in reducing ischemic injury as compared to HP with RL.

Keywords Hypothermic perfusion .

Total vascular exclusion $\cdot$ Reperfusion $\cdot$ Liver $\cdot$ Celsior

\section{Introduction}

Total vascular exclusion (TVE) consists of clamping of the portal vein, the hepatic artery, and the supra and infrahepatic caval vein [1]. It is applied during extended liver resection when backflow from the caval vein causes significant blood loss or when part of the caval vein is involved in the tumor. TVE leads to hepatic ischemia and subsequent reperfusion (I-R) injury when the clamps are removed and normal blood flow to the liver is restored. Especially in patients with underlying liver disease, hepatic ischemia for periods longer than 60 min leads to increased risk of liver failure and death [2-4]. Liver I-R injury is caused by the release of reactive oxygen species and the onset of an inflammatory response by Kupffer cells. This leads to further damage of the parenchymal and sinusoidal endothelial cells, leading to necrosis, apoptosis, and microcirculatory failure $[5,6]$.

In situ hypothermic perfusion (HP) of the liver during TVE is an option to reduce hepatic I-R injury during extensive liver resections [7-12]. The protective effect of HP is based on the concept that hypothermia leads to diminished metabolism and, hence, decreased energy and oxygen demand. Ringer-lactate (RL) is one of the most often used solutions for HP [7, 11]. It is a crystalloid solution without any additives and without buffering capacity. The aim of HP with Ringer-lactate solution is 
solely to cool the liver and thereby to decrease metabolism and the need for oxygen. At $28^{\circ} \mathrm{C}$, however, cellular metabolism and oxygen demand is still around 50\% [13]. Next to RL solution, organ preservation solutions have also been applied during HP $[8,9]$. The advantage of organ preservation solutions lies in their ability to prevent tissue acidosis, cell swelling, free radical damage, and energy depletion, all phenomena which occur during ischemia and subsequent reperfusion. A relatively new organ preservation solution, called Celsior (Cs) solution, has also shown to be effective in both experimental and clinical organ preservation [14-21]. It was originally designed for donor heart and lung preservation but has also proven to be suitable for the preservation of liver grafts $[15,18,21]$. Cs contains reduced glutathione which has a strong antioxidative effect. Also, glutathione plays a role in preserving endothelial function by enhancing endothelium-dependent NO release, as has been demonstrated in pulmonary grafts $[22,23]$. Cs also contains mannitol and lactobionate to prevent cell swelling and glutamate for energy supply. Histidine buffer has been added to prevent tissue acidosis and magnesium sulphate acts as a membrane stabilizer.

The aim of this study was to assess whether in situ HP during TVE using Cs shows a benefit above RL solution in terms of further diminishing liver damage and preserving endothelial cell integrity and microcirculation. TVE with HP using Cs or RL was also compared with TVE without HP.

\section{Animals and methods}

\section{Animals}

Twenty male pigs (Vendrig, Amsterdam, The Netherlands) were used, weighing $40-50 \mathrm{~kg}$. All pigs were allowed to acclimatize to the laboratory environment for 7 days with free access to standard laboratory food (Blok, Woerden, The Netherlands) and water. Pigs were fasted overnight with free access to water before the experiments. The experiments were approved by the Animal Ethics Committee of the Academic Medical Center, University of Amsterdam, The Netherlands.

\section{Anesthesia}

Methods concerning premedication and anesthesia were described previously [12]. Blood temperature, measured in the brachiocephalic vein, was continuously monitored and a physiological body temperature of $37-38^{\circ} \mathrm{C}$ was maintained by means of a heating lamp and a heating mat. Arterial blood gas analysis was performed before and at regular intervals after TVE (ABL 505/OSM 3 HEMOXIMETER ${ }^{\circledR}$, Copenhagen, Denmark). Metabolic acidosis was corrected with $8.4 \% \mathrm{HCO}_{3}{ }^{-}$(Fresenius Kabi Nederland B. V.'s, Hertogenbosch, The Netherlands).

\section{Surgical procedure}

A midline laparotomy was performed followed by dissection (Force $^{\mathrm{TM}}$ 20, Valleylab, Boulder, USA) and cannulation of the common bile duct for continuous measurement of bile production. Another cannula was placed into the distal common bile duct and the duodenum to return the bile to the intestine of the animal during the experiment. The portal vein, the hepatic artery, and the caval vein were dissected free and the right gastric and the gastroduodenal artery were divided together with the right gastric vein in order to cut off any accessory blood supply to the liver. TVE was achieved by clamping of the infra and suprahepatic caval vein, the common hepatic artery, and the portal vein. To prevent splanchnic congestion and venous congestion in the lower limbs, a situation that is lethal in pigs, a polyethylene prosthesis with one side port was used to bypass blood from the infrahepatic caval vein and portal vein to the suprahepatic caval vein through a transverse incision in the infrahepatic caval vein.

The prosthesis was inserted and guided intralumenally in cranial direction. It was fixed into the caval vein using two slings, which were placed in suprahepatic as well as in infrahepatic position. Then, the portal vein was divided and the proximal end was connected to the side port of the prosthesis after which the clamps were removed from the caval vein and portal vein. The distal end of the portal vein was used to perfuse the liver with cold RL or Cs solution. The perfusate was allowed to drain through the transverse incision of the caval vein into the abdominal cavity, from where it was removed.

After 60 min of TVE, the perfusion was stopped and the proximal portal vein was reconnected to the distal end. A ligature was placed cranially from the side port around the infrahepatic caval vein (to secure the intraluminal prosthesis and to prevent blood from entering the abdominal cavity after reperfusion of the liver) and the sling around the suprahepatic caval vein was removed. The liver was then reperfused by releasing the clamps from the portal vein and the common hepatic artery and the abdomen was closed.

\section{Experimental design}

All 20 pigs underwent 60 min of TVE followed by $24 \mathrm{~h}$ of reperfusion. The animals were randomly divided into three groups. In the first group, TVE was performed without HP (no-HP group; $n=6$ ). In the second group, livers were perfused with ice-cold RL solution with an average core liver temperature of $28^{\circ} \mathrm{C}$ (RL group; $n=6$ ). In the third group, livers were perfused with ice-cold $\mathrm{Cs}$ solution also maintaining an average core liver temperature of $28^{\circ} \mathrm{C}$ (Cs group; 
$n=5$ ). It was originally planned to have six animals in each group. Three animals were added to the no-HP group because three animals died before the end of the experiment, making a total of 20 pigs (see "Results" section). Only the six pigs that survived the whole experiment in the no-HP group were used for data analysis. The Cs group only included five animals because significant differences were already found with five animals, and the Animal Ethics Committee advised not to add the sixth animal to this group.

The components of the two perfusion solutions are shown in Table 1. Total perfusion volumes were 5,100 \pm 467 $\mathrm{mL}$ in the $\mathrm{RL}$ group and $6,020 \pm 455 \mathrm{~mL}$ in the Cs group $(P=0.39)$. Core liver temperature was measured by two temperature probes (Metatemp, Industrial Temperature Measurement, Steenbergen, The Netherlands) and monitored continuously (Thermistor 4070, Mallinckrodt, St. Louis, USA). The probes were placed in the right lateral and the left medial liver lobes. The tip was placed $4-5 \mathrm{~cm}$ within the liver tissue.

The average temperature was used for adjusting the flow of the perfusion solution. Perfusion was powered by a roller pump (Gambro Instrumenta $\mathrm{AB}$, Lund, Sweden) and the flow was adjusted from 50 to $500 \mathrm{~mL} / \mathrm{h}$ depending on the core liver temperature. Flow was started at $100-200 \mathrm{~mL} / \mathrm{hr}$ and when the target core liver temperature was attained, flow was adjusted to $50 \mathrm{~mL} / \mathrm{h}$, to maintain core liver temperature at the desired level. In the group without perfusion, liver temperature was maintained at $37-38^{\circ} \mathrm{C}$. After TVE and reperfusion, the pigs remained under anesthesia for $24 \mathrm{~h}$ after which they were sacrificed.

Hepatocellular injury

To assess hepatocellular injury, aspartate aminotransferase (AST) and alanine aminotransferase (ALT) concentrations were measured in arterial blood samples taken before TVE

Table 1 Components of perfusion solutions ( $\mathrm{mmol} / \mathrm{L}$ )

\begin{tabular}{lcc}
\hline & Ringer-lactate & Celsior \\
\hline Calcium & 1.80 & 0.25 \\
Chloride & 111 & 41.5 \\
Glutamate & & 20 \\
Glutathione & & 3 \\
Histidine & & 30 \\
Hydroxide & 29 & 100 \\
Lactate & & \\
Lactobionate & & 80 \\
Magnesium & 5.40 & 13 \\
Mannitol & 131 & 60 \\
Potassium & & 15 \\
Sodium & & 100 \\
Osmolality & 6.0 & $320 \mathrm{mOsm} / \mathrm{kg}$ \\
pH & $\mathrm{mOsm} / \mathrm{L}$ & 7.3 \\
\hline
\end{tabular}

and after $1,6,12$, and $24 \mathrm{~h}$ of reperfusion using routine laboratory techniques.

Hepatic pedicle blood flow

Portal vein and hepatic artery blood flow were monitored continuously (Transonic Systems, A.B. Medical B.V., Roermond, The Netherlands).

\section{Microvascular perfusion}

Microvascular perfusion was assessed by performing intrahepatic tissue $\mathrm{pO}_{2}$ measurements using a polarographic $\mathrm{pO}_{2}$ needle electrode (SIGMA pO 2 -Histograph KIMOC, Eppendorf, Hamburg, Germany), as described previously [24, 25]. A $\mathrm{pO}_{2}$ histogram was constructed from 100 consecutive $\mathrm{pO}_{2}$ values obtained by stepwise withdrawal of the needle over a $2-\mathrm{cm}$ tract (pilgrim step method) in the right median liver lobe. Intrahepatic $\mathrm{pO}_{2}$ measurements were performed before TVE and after TVE at $10 \mathrm{~min}$ and 1 and $24 \mathrm{~h}$.

\section{Glutathione concentration}

Glutathione concentrations were measured in liver tissue, bile, and blood plasma according to the method of Tietze [26]. Liver biopsies were taken from the rim of the right medial liver lobe. The biopsies were homogenized in $1-\mathrm{mL}$ ice-cold phosphate-buffered saline. After protein determination (bicinchoninic acid protein assay, Pierce) in liver tissue homogenates, $3.6 \mathrm{~mL}$ metaphosphoric acid $(50 \mathrm{~g} / \mathrm{L})$ was added to the homogenates, bile, and plasma samples and the suspensions were vortexed and centrifuged (4,500 rpm, $10 \mathrm{~min})$. Supernatants were used for glutathione measurements. Total (oxidized and reduced) glutathione concentrations were measured before and $10 \mathrm{~min}$ and 1,6 , and $24 \mathrm{~h}$ after TVE.

Coagulation parameters

Prothrombin time (PT) was determined using a one-stage clotting assay and Thromborel-S thromboplastin (Dade Behring, Leusden, The Netherlands). The plasma concentration of thrombin-antithrombin complexes (TAT) were measured by enzyme-linked immunosorbent assay (Enzygnost TAT, Dade Behring, Leusden, The Netherlands).

Statistical analysis

Results are expressed as mean \pm standard error of the mean. Statistical analysis was performed using Statistical Package for Social Sciences (SPSS) 12.0.1 for Windows (SPSS Inc., Chicago, IL, USA). One-way analysis of variance (ANOVA) followed by Bonferroni posttest was used for differences 
between groups. Repeated-measures ANOVA was used for measurements at multiple time points followed by Bonferroni posttest for differences between groups or paired $t$-test for differences within groups at different time points. A $p$-value $<0.05$ was considered significant.

\section{Results}

\section{Survival}

Three animals (33\%) in the no-HP group died shortly after TVE. Death in these animals was caused by massive congestion of the liver leading to noncontrollable hypotensive shock, highly elevated heart rate, and eventually cardiac arrhythmia and arrest. To increase the sample size in the no-HP group, three animals were added making a total of $n=6$ in this group. No animals died during the experiment in the other groups.

\section{Arterial blood gas analysis}

After reperfusion, the first arterial blood gas analysis was performed at $10 \mathrm{~min}$. Abnormal values found on these analyses were immediately corrected by adjusting ventilation (for $\mathrm{pO}_{2}$ or $\mathrm{pCO}_{2}$ abnormalities) and/or infusion of $\mathrm{HCO}_{3}^{-}$(for metabolic acidosis). On these analyses, significantly lower arterial $\mathrm{pH}$ and base excess values were found in the no-HP group and the RL group as compared to the $\mathrm{CE}$ group (Table 2). In all groups, arterial $\mathrm{pH}$ and base excess values were significantly lower after 10-min reperfusion as compared to before TVE.

\section{Parenchymal injury}

AST was significantly elevated in the no-HP group as compared to the RL group and the Cs group after TVE (Fig. 1a). No statistical differences were found between the RL group and the CE group. ALT values showed a similar pattern (data not shown).

Table 2 Arterial $\mathrm{pH}$ and base excess values before and after 10-min reperfusion

\begin{tabular}{lccc}
\hline & no-HP $(n=6)^{\mathrm{a}}$ & $\mathrm{RL}(n=6)$ & $\mathrm{Cs}(n=5)$ \\
\hline Arterial pH & & & \\
Pre-TVE & $7.43 \pm 0.03 \mathrm{a}$ & $7.43 \pm 0.02 \mathrm{c}$ & $7.45 \pm 0.02 \mathrm{e}$ \\
$10 \mathrm{~min}$ rep. & $7.20 \pm 0.02 \mathrm{ab}$ & $7.23 \pm 0.02 \mathrm{~cd}$ & $7.31 \pm 0.02 \mathrm{bde}$ \\
Arterial base excess $(\mathrm{mmol} / \mathrm{L})$ & & \\
Pre-TVE & $3.1 \pm 1.6 \mathrm{f}$ & $3.8 \pm 0.6 \mathrm{~h}$ & $3.5 \pm 1.3 \mathrm{j}$ \\
10-min rep. & $-7.7 \pm 0.4 \mathrm{fg}$ & $-6.7 \pm 0.4 \mathrm{hi}$ & $-4.1 \pm 0.9 \mathrm{gij}$ \\
\hline
\end{tabular}

Values with the same letters are significantly different $(p<0.05)$.

${ }^{a}$ Only animals that survived the whole experiment are included.
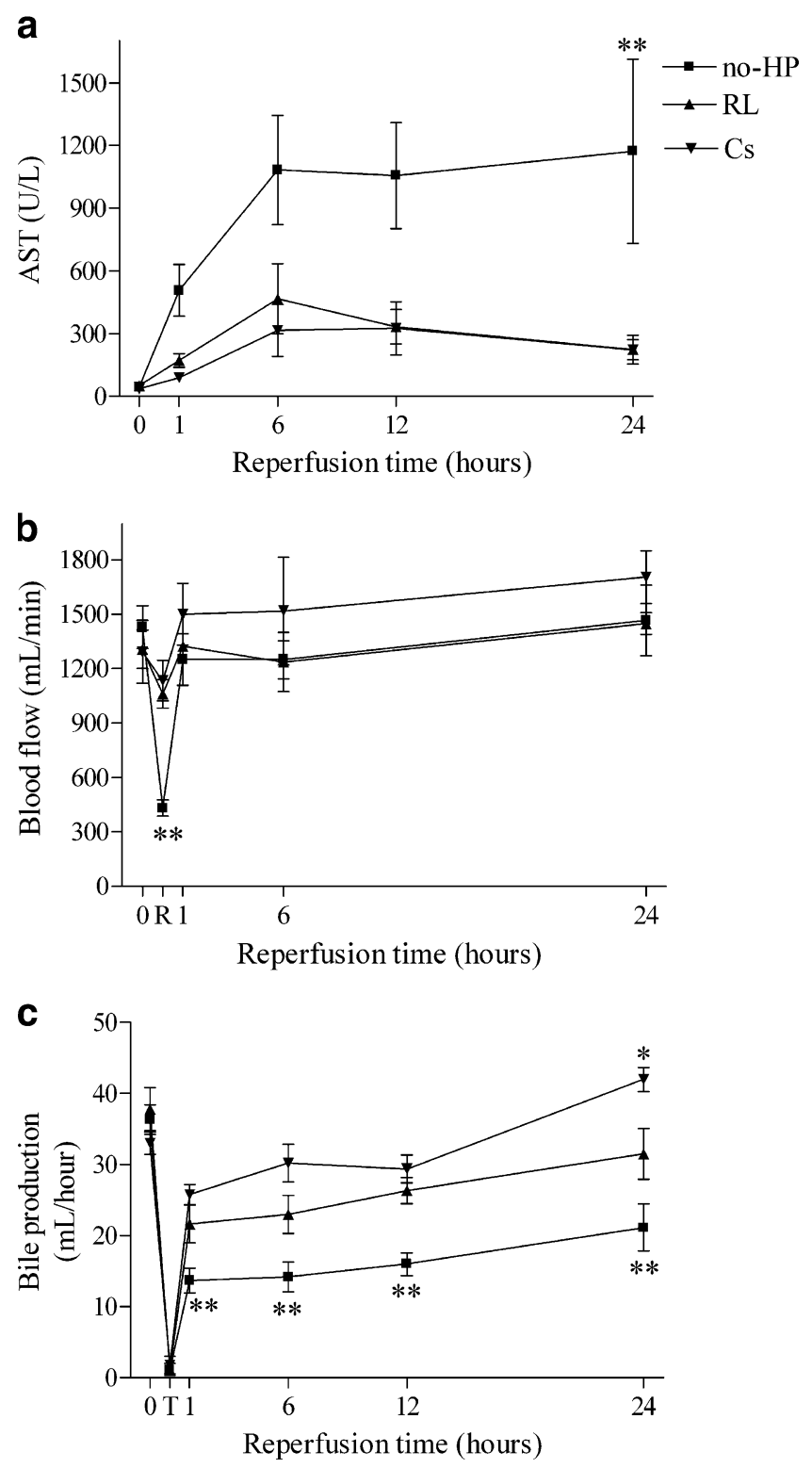

Fig. 1 Aspartate aminotransferase (AST) levels (a), combined hepatic artery and portal venous blood flow (b) and bile production (c), measured before TVE, at the end of TVE (T), 10 min after TVE (R), and 1, 6, 12 and $24 \mathrm{~h}$ after TVE. a AST values were significantly lower in the RL group and the Cs group compared to the no-HP group (** repeated measures ANOVA, $p=0.042$ ). No differences in AST were found between the RL group and the Cs group. b After 10-min reperfusion, blood flow was significantly decreased in no-HP as compared to the other groups $(* * p<0.02)$. No significant differences were found in blood flow on the other time points. $\mathbf{c}$ Bile production was significantly higher in the $\mathrm{RL}$ group and the Cs group as compared to the no-HP group at all time points after TVE $(* * p<0.05)$. After $24-\mathrm{h}$ reperfusion, bile production was significantly higher in the Cs group as compared to the no-HP group and the RL group $(* p<0.05)$

Vascular inflow into the liver

Decreased flow through the liver was found immediately after reperfusion in animals that did not undergo HP. Combined blood flow in the hepatic artery and the portal 
vein was significantly lower in the no-HP group as compared to the RL and Cs groups, $10 \mathrm{~min}$ after reperfusion (Fig. 1b). Flow subsequently normalized in all groups and no significant differences were found anymore.

Bile production

Baseline bile production was $35-40 \mathrm{~mL} / \mathrm{h}$. During TVE, bile production decreased to almost zero (Fig. 1c). After release of the clamps, bile production gradually increased in all groups. After 1-, 6-, and 12-h reperfusion, bile production was significantly higher in the RL and Cs groups as compared to the no-HP group. After 24-h reperfusion, bile production was significantly higher in the Cs group as compared to the no-HP and RL groups.

\section{Microvascular perfusion}

Microvascular perfusion, as measured by intrahepatic tissue $\mathrm{pO}_{2}$ levels, decreased significantly $10 \mathrm{~min}$ after reperfusion as compared to pre-TVE values in the no-HP group (Fig. 2). After 1-h reperfusion, microvascular perfusion was significantly increased in the Cs group as compared to before TVE. This relative hyperperfusion also occurred to a lesser extent in the RL group but not in the no-HP group. After 24-h reperfusion, intrahepatic tissue $\mathrm{pO}_{2}$ levels had normalized in all groups.

\section{Glutathione levels}

After reperfusion, liver tissue glutathione significantly decreased in the no-HP group as compared to pre-TVE (Fig. 3a). This did not occur in the other groups. After 10-min and 6-h reperfusion, liver tissue glutathione was significantly higher in the Cs group as compared to the

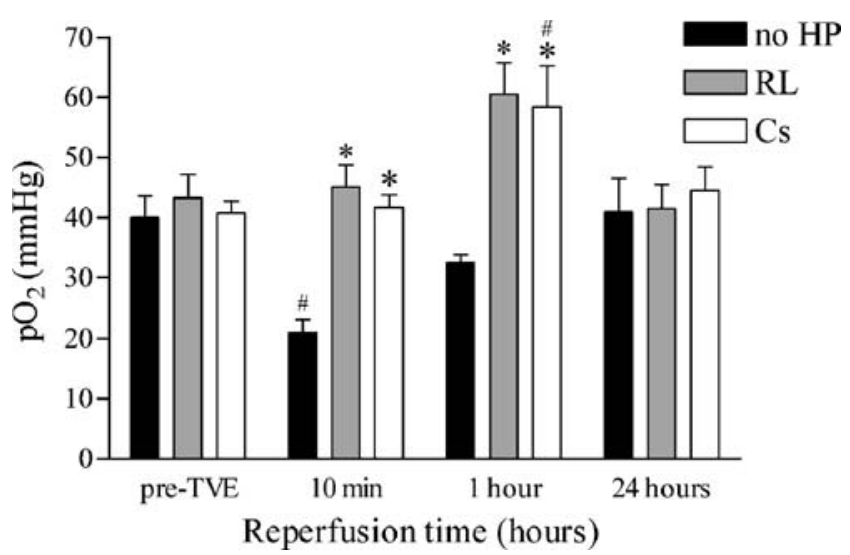

Fig. 2 Intrahepatic tissue $\mathrm{pO}_{2}$ levels before TVE and during reperfusion. Intrahepatic tissue $\mathrm{pO}_{2}$ was significantly lower in the no-HP group (black bars) as compared to the RL (grey bars) and Cs (white bars) groups $(* p<0.01)$ after 10 -min and 1 -h reperfusion. \# Significantly different from pre-TVE $(p<0.05)$
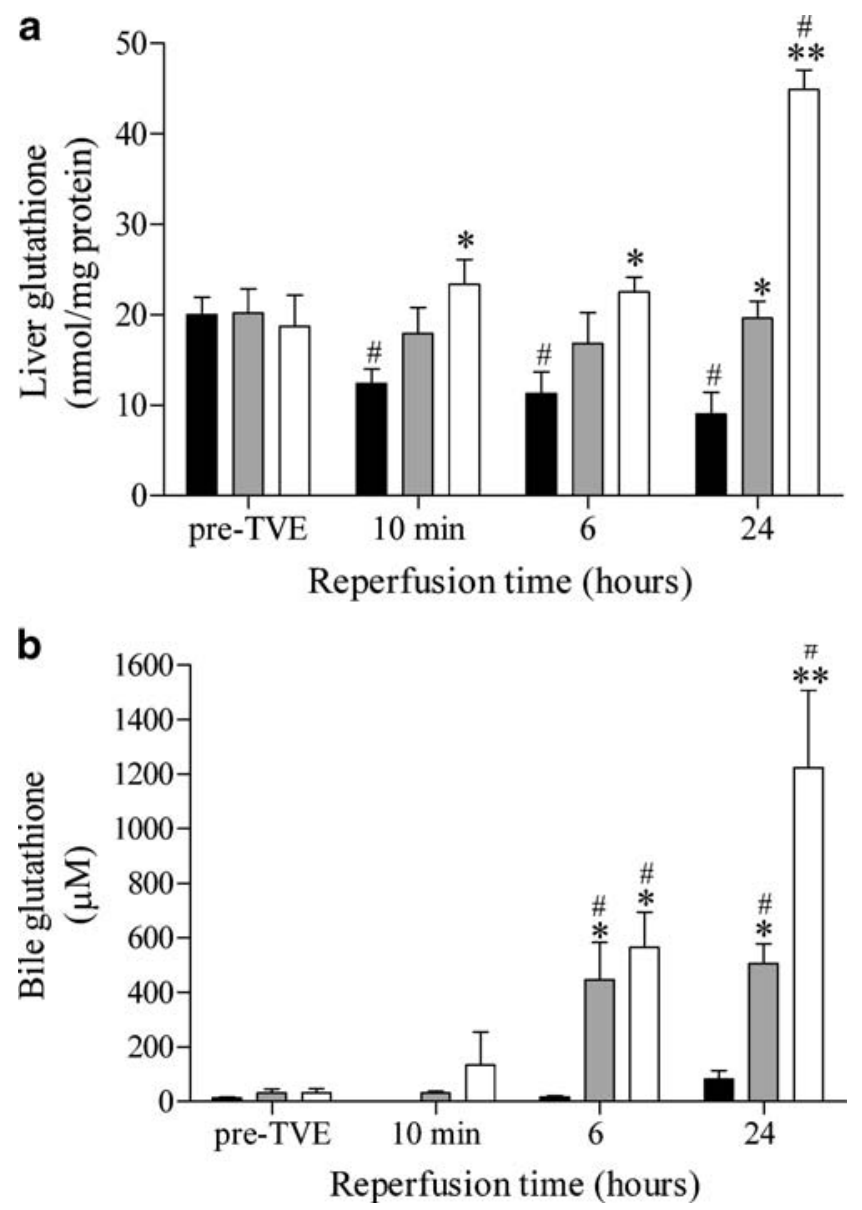

Fig. 3 Liver tissue (a) and bile (b) glutathione concentration, measured before TVE and during reperfusion. a After 10-min and 6-h reperfusion, liver tissue glutathione was significantly higher in the Cs group as compared to no-HP $(* p=0.042)$. After 24 -h reperfusion, liver tissue glutathione was significantly higher in the RL as compared to no-HP $(* p<0.05)$ and also in the Cs group as compared to RL and no-HP $(* * p<0.02)$. b After 6- and 24-h reperfusion, bile glutathione was significantly higher in the RL and Cs groups as compared to the no-HP group $(* p<0.05)$. Bile glutathione was also significantly higher in the Cs group as compared to the RL group after 24-h reperfusion (** $p=$ $0.031)$. \# Significantly different from pre-TVE $(p<0.05)$

no-HP group. After 24-h reperfusion, liver tissue glutathione was significantly higher in the RL and Cs groups as compared to the no-HP group. Liver tissue glutathione was also higher in the Cs group as compared to the RL group after 24-h reperfusion. Liver tissue glutathione was significantly higher in the Cs group after 24-h reperfusion as compared to pre-TVE. During reperfusion, bile glutathione significantly increased in the RL and $\mathrm{Cs}$ groups as compared to pre-TVE (Fig. 3b). After 6- and 24-h reperfusion, bile glutathione was significantly higher in the RL and Cs groups as compared to the no-HP group. Bile glutathione was also significantly higher in the Cs group as compared to the RL group after 24-h reperfusion. Plasma glutathione levels during reperfusion showed no differences 
between groups nor when compared to pre-TVE values (data not shown).

\section{Coagulation parameters}

The function of the coagulation system, as assessed by PT, significantly decreased at all time points after TVE in all groups (Fig. 4a). After 12- and 24-h reperfusion, PT was significantly prolonged in the no-HP group as compared to the RL and Cs groups. After 24-h reperfusion, PT was also significantly higher in the RL group as compared to the Cs group. Only in the Cs group, PT values almost returned to baseline values after $24-\mathrm{h}$ reperfusion. Activation of coagulation, leading to thrombin generation, as measured by plasma TAT complexes, was significantly increased at all time points during reperfusion as compared to before TVE in all groups (Fig. 4b). After TVE, TAT complexes were significantly higher in the no-HP group as compared to the RL and Cs groups. No statistical differences in TAT complexes were found between RL and Cs groups.
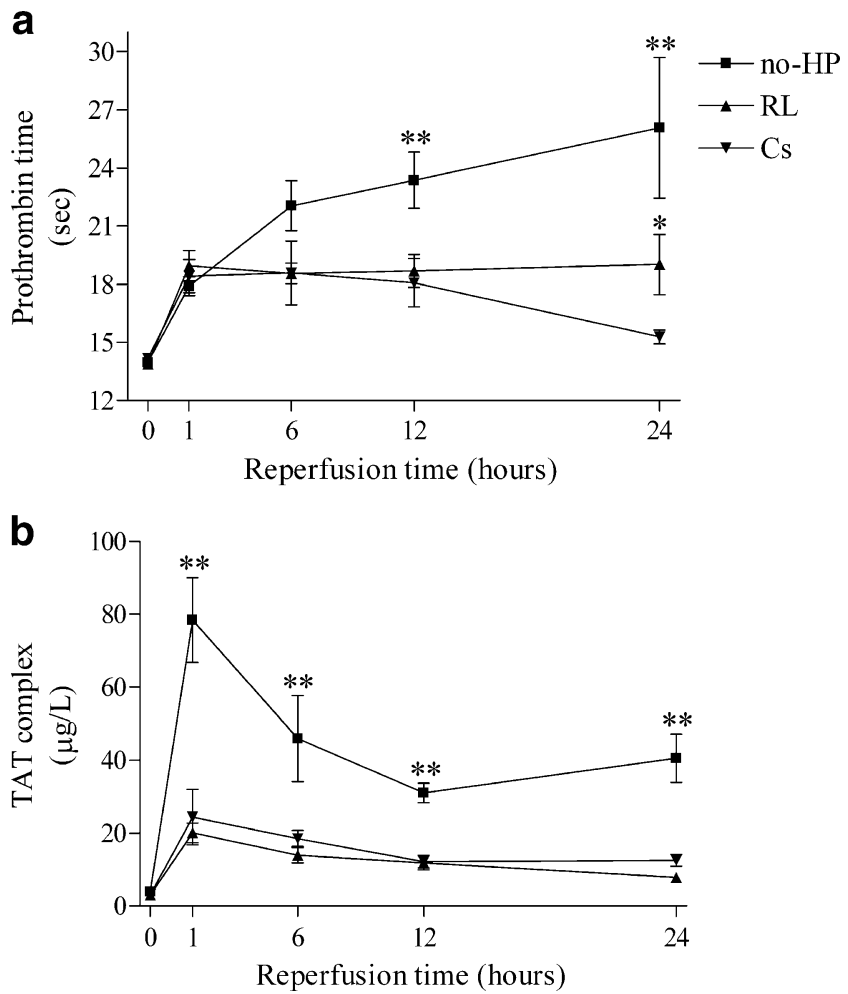

Fig. 4 Prothrombin time (a) and thrombin-antithrombin (TAT) complexes (b) measured before TVE and during reperfusion. a PT was significantly higher at all time points after reperfusion as compared to before TVE in all groups $(p<0.05)$. After 12- and 24-h reperfusion, PT was significantly higher in the no-HP group as compared to the RL and Cs groups $(* * p<0.05)$. After 24 -h reperfusion, PT also was significantly higher in the RL group as compared to the Cs group $(* p=0.035)$. b TAT complexes were significantly higher at all time points during reperfusion as compared to before TVE in all groups $(p<0.05)$. After 1-, 6-, 12-, and 24-h reperfusion, TAT complexes were significantly higher in the no-HP group as compared to the RL and Cs groups $(* * p<0.05)$

\section{Discussion}

The effect of in situ HP using Celsior solution, a relatively new organ preservation solution, was compared with HP using Ringer-lactate and no-HP during 60-min TVE of porcine liver. The advantage of HP during TVE was confirmed in this study and is in agreement with other reports [7-12]. Although no differences in parenchymal damage and microcirculatory perfusion were found, HP with Celsior solution resulted in less decrease of arterial $\mathrm{pH}$ and base loss, better restoration of bile production, more radical scavenging capacity, and better maintenance of coagulation capacity as compared to HP with Ringer-lactate solution. Hence, HP with Celsior solution is advantageous over HP with Ringer-lactate solution. The arterial pH drop and base loss observed directly after reperfusion was probably caused by the onset of anaerobic glycolysis due to the lack of oxygen. This leads to metabolic acidosis secondary to the formation of lactate. Whereas acidotic $\mathrm{pH}$ can protect against anoxic cell death, reperfusion of ischemic cells at acidotic $\mathrm{pH}$ leads to more cell killing ( $\mathrm{pH}$ paradox) $[27,28]$. The minor decrease in arterial $\mathrm{pH}$ and base loss in the Celsior group as compared to the Ringer-lactate group is most likely caused by the histidine buffer contained in Celsior. Ringer-lactate solution does not have a buffer capacity and has a low $\mathrm{pH}(6.0)$ by itself.

Formation of reactive oxygen species is an important step in the onset of I-R damage [5, 6]. Reduced glutathione is known to be a potent radical scavenger and has shown the ability to reduce I-R damage in different models [29, 30]. Increased radical scavenging capacity in HP with Celsior solution, as shown by total liver glutathione levels, was most pronounced after 24-h reperfusion but was already visible after 10-min reperfusion. It is hypothesized that the reduced glutathione in Celsior solution was directly oxidized in the liver during TVE. As known from literature, oxidized glutathione is excreted into the bile [26]. Accordingly, glutathione levels were most pronounced in the Celsior group. It was seen earlier after reperfusion and peaked after 24-h reperfusion. Peak values of liver and bile glutathione after 24-h reperfusion probably better reflect the restorative capacity of glutathione. Leakage of glutathione from damaged cells into the systemic circulation did not appear to be a major factor in this study, as no differences were found in plasma glutathione levels after TVE as compared to pre-TVE in all groups.

Microcirculatory disturbances within the liver were most apparent directly after reperfusion. Hepatic artery and portal venous flow as well as intrahepatic $\mathrm{pO}_{2}$ levels were decreased after 10-min reperfusion and subsequently recovered in the no-HP group. In the animals that did not survive the experiments, this no-reflow state persisted and was accompanied by massive congestion of the liver and 
noncorrectable systemic shock. Activation of coagulation is also known to occur as part of I-R injury [31, 32]. The formation of TAT complexes was significantly increased in the no-HP group. HP with Celsior solution not only resulted in reduction of the formation of TAT complexes, but also PT was almost normalized within $24 \mathrm{~h}$ of reperfusion. So HP with Celsior solution leads to faster restoration of liver synthesis function as compared to HP with Ringer-lactate, while coagulation activation is equally reduced. The restoration of liver synthesis function by Celsior, measured with PT, is remarkable and has not been described previously.

From organ preservation studies it is known that additives such as energy supplements, $\mathrm{pH}$ buffer, and membrane stabilizers can decrease cold ischemic damage and prolong preservation periods [13]. Although organ preservation solutions such as University of Wisconsin (UW) solution have been used for HP, no comparative studies with Ringer-lactate have been performed [9, 10]. Currently, many consider UW solution as the gold standard in organ preservation. In our experience, however, UW has some disadvantages. Due to the colloid hydroxyethyl starch, UW solution has a relatively high viscosity, rendering it difficult to use as a washout solution. Furthermore, it is an intracellular type solution containing a high potassium concentration $(120 \mathrm{mmol} / \mathrm{L})$. Therefore, it is potentially dangerous to use in situ because of the risk of cardiac arrhythmias when UW is spilled into the systemic circulation. Celsior solution is a relatively new organ preservation solution with a lower potassium concentration $(15 \mathrm{mmol} / \mathrm{L})$ and lower viscosity than UW solution. We therefore decided to use Celsior solution in this study.

In humans, in situ HP of the liver during TVE resulted in a drastic reduction of parenchymal damage during liver resection and decreased post-operative complications [9]. Although TVE may only be needed in complex liver resections, it is advised to use HP during TVE, even when the expected duration of TVE is below $60 \mathrm{~min}$. The safe limit for vascular inflow occlusion during partial liver resections has not been defined. A period of $60 \mathrm{~min}$ is considered to be relatively safe in humans, depending on quality of the liver parenchyma [33]. In our pig model, however, TVE for $60 \mathrm{~min}$ without HP resulted in a $33 \%$ mortality rate (3/9). When, during pilot experiments, TVE duration was extended to $90 \mathrm{~min}$, no animals survived $(0 / 3)$. These results confirm the fact that the pig liver is more susceptible to I-R damage than the human liver, and in order to test different perfusion solutions, a period of 60-min TVE suffices in the pig model.

In conclusion, the protective effect of in situ HP during TVE was confirmed in this study. Furthermore, whereas no difference in parenchymal damage or microcirculatory disturbances were found, HP with Celsior solution was more effective in reducing metabolic acidosis, restoring radical scavenging capacity and bile production, and maintaining coagulation capacity as compared to HP with Ringer-lactate. Therefore, when applying HP in humans, Celsior is considered the preferred perfusion solution.

Acknowledgements Authors wish to thank IMTIX for kindly providing Celsior.

Open Access This article is distributed under the terms of the Creative Commons Attribution Noncommercial License which permits any noncommercial use, distribution, and reproduction in any medium, provided the original author(s) and source are credited.

\section{References}

1. Bismuth H, Castaing D, Garden OJ (1989) Major hepatic resection under total vascular exclusion. Ann Surg 210(1):13-19

2. Delva E, Camus Y, Nordlinger B, Hannoun L, Parc R, Deriaz H, Lienhart A, Huguet C (1989) Vascular occlusions for liver resections. Operative management and tolerance to hepatic ischemia: 142 cases. Ann Surg 209(2):211-218

3. Huguet C, Gavelli A, Bona S (1994) Hepatic resection with ischemia of the liver exceeding one hour. J Am Coll Surg 178 (5):454-458

4. Man K, Fan ST, Ng IO, Lo CM, Liu CL, Wong J (1997) Prospective evaluation of Pringle maneuver in hepatectomy for liver tumors by a randomized study. Ann Surg 226(6):704-711

5. Teoh NC, Farrell GC (2003) Hepatic ischemia reperfusion injury: pathogenic mechanisms and basis for hepatoprotection. J Gastroenterol Hepatol 18(8):891-902

6. Jaeschke H (1998) Mechanisms of reperfusion injury after warm ischemia of the liver. J Hepatobiliary Pancreat Surg 5(4):402-408

7. Fortner JG, Shiu MH, Kinne DW, Kim DK, Castro EB, Watson RC, Howland WS, Beattie EJ Jr (1974) Major hepatic resection using vascular isolation and hypothermic perfusion. Ann Surg 180 (4):644-652

8. Hannoun L, Delriviere L, Gibbs P, Borie D, Vaillant JC, Delva E (1996) Major extended hepatic resections in diseased livers using hypothermic protection: preliminary results from the first 12 patients treated with this new technique. J Am Coll Surg 183 (6):597-605

9. Azoulay D, Eshkenazy R, Andreani P, Castaing D, Adam R, Ichai P, Naili S, Vinet E, Saliba F, Lemoine A, Gillon MC, Bismuth H (2005) In situ hypothermic perfusion of the liver versus standard total vascular exclusion for complex liver resection. Ann Surg 241 (2):277-285

10. Vaillant JC, Borie DC, Hannoun L (1998) Hepatectomy with hypothermic perfusion of the liver. Hepatogastroenterology 45 (20):381-388

11. Kaiho T, Tanaka T, Tsuchiya S, Yanagisawa S, Takeuchi O, Miura M, Saigusa N, Kitakata Y, Miyazaki M (2003) Hepatic resection under in situ hypothermic hepatic perfusion. Hepatogastroenterology 50(51):761-765

12. Heijnen BH, Straatsburg IH, Gouma DJ, van Gulik TM (2003) Decrease in core liver temperature with 10 degrees $\mathrm{C}$ by in situ hypothermic perfusion under total hepatic vascular exclusion reduces liver ischemia and reperfusion injury during partial hepatectomy in pigs. Surgery 134(5):806-817 
13. Belzer FO, Southard JH (1988) Principles of solid-organ preservation by cold storage. Transplantation 45(4):673-676

14. Boggi U, Vistoli F, Del Chiaro M, Signori S, Croce C, Pietrabissa A, Berchiolli R, Marchetti P, Prato SD, Mosca F (2004) Pancreas preservation with University of Wisconsin and Celsior solutions: a single-center, prospective, randomized pilot study. Transplantation 77(8):1186-1190

15. Audet M, Alexandre E, Mustun A, David P, Chenard-Neu MP, Tiollier J, Jaeck D, Cinqualbre J, Wolf P, Boudjema K (2001) Comparative evaluation of Celsior solution versus Viaspan in a pig liver transplantation model. Transplantation 71(12):1731-1735

16. Abrahamse ST, Dinant S, Pfaffendorf M, van Gulik TM (2002) In vitro function of porcine carotid arteries preserved in UW, HTK and Celsior solutions. Fundam Clin Pharmacol 16(6):503-511

17. Xiong L, Legagneux J, Wassef M, Oubenaissa A, Detruit H, Mouas C, Menasche P (1999) Protective effects of Celsior in lung transplantation. J Heart Lung Transplant 18(4):320-327

18. Pedotti P, Cardillo M, Rigotti P, Gerunda G, Merenda R, Cillo U, Zanus G, Baccarani U, Berardinelli ML, Boschiero L, Caccamo L, Calconi G, Chiaramonte S, Dal Canton A, De Carlis L, Di Carlo V, Donati D, Montanaro D, Pulvirenti A, Remuzzi G, Sandrini S, Valente U, Scalamogna M (2004) A comparative prospective study of two available solutions for kidney and liver preservation. Transplantation 77(10):1540-1545

19. Straatsburg IH, Abrahamse SL, Song SW, Hartman RJ, Van Gulik TM (2002) Evaluation of rat liver apoptotic and necrotic cell death after cold storage using UW, HTK, and Celsior. Transplantation 74(4):458-464

20. Abrahamse SL, van Runnard HP, Hartman RJ, Chamuleau RA, van Gulik TM (2003) Induction of necrosis and DNA fragmentation during hypothermic preservation of hepatocytes in UW, HTK, and Celsior solutions. Cell Transplant 12(1):59-68

21. Cavallari A, Cillo U, Nardo B, Filipponi F, Gringeri E, Montalti R, Vistoli F, D'amico F, Faenza A, Mosca F, Vitale A, D'amico D (2003) A multicenter pilot prospective study comparing Celsior and University of Wisconsin preserving solutions for use in liver transplantation. Liver Transpl 9(8):814-821

22. Prasad A, Andrews NP, Padder FA, Husain M, Quyyumi AA (1999) Glutathione reverses endothelial dysfunction and improves nitric oxide bioavailability. J Am Coll Cardiol 34(2):507-514
23. Sommer SP, Gohrbandt B, Fischer S, Hohlfeld JM, Warnecke G, Avsar M, Struber M (2005) Glutathione improves the function of porcine pulmonary grafts stored for twenty-four hours in lowpotassium dextran solution. J Thorac Cardiovasc Surg 130(3): 864-869

24. van Wagensveld BA, van Gulik TM, Gabeler EE, van der Kleij AJ, Obertop H, Gouma DJ (1998) Intrahepatic tissue pO2 during continuous or intermittent vascular inflow occlusion in a pig liver resection model. Eur Surg Res 30(1):13-25

25. Heijnen BH, Straatsburg IH, Kager LM, van der Kleij AJ, Gouma DJ, van Gulik TM (2003) Effect of in situ hypothermic perfusion on intrahepatic pO2 and reactive oxygen species formation after partial hepatectomy under total hepatic vascular exclusion in pigs. Liver Int 23(1):19-27

26. Tietze F (1969) Enzymic method for quantitative determination of nanogram amounts of total and oxidized glutathione: applications to mammalian blood and other tissues. Anal Biochem 27(3):502-522

27. Currin RT, Gores GJ, Thurman RG, Lemasters JJ (1991) Protection by acidotic $\mathrm{pH}$ against anoxic cell killing in perfused rat liver: evidence for a $\mathrm{pH}$ paradox. FASEB J 5(2):207-210

28. Bond JM, Chacon E, Herman B, Lemasters JJ (1993) Intracellular $\mathrm{pH}$ and $\mathrm{Ca} 2+$ homeostasis in the $\mathrm{pH}$ paradox of reperfusion injury to neonatal rat cardiac myocytes. Am J Physiol 265(1 Pt 1):C129-C137

29. Schauer RJ, Gerbes AL, Vonier D, Meissner H, Michl P, Leiderer R, Schildberg FW, Messmer K, Bilzer M (2004) Glutathione protects the rat liver against reperfusion injury after prolonged warm ischemia. Ann Surg 239(2):220-231

30. Zhou L, Rui JA, Zhou RL, Peng XM, Wang SB, Chen SG, Chen SG, Qu Q, Zhao YP (2004) Liver injury after intermittent or continuous hepatic pedicle clamping and its protection by reduced glutathione. Hepatobiliary Pancreat Dis Int 3(2):209-213

31. Schoots IG, Levi M, Roossink EH, Bijlsma PB, van Gulik TM (2003) Local intravascular coagulation and fibrin deposition on intestinal ischemia-reperfusion in rats. Surgery 133(4):411-419

32. Okajima K, Harada N, Kushimoto S, Uchiba M (2002) Role of microthrombus formation in the development of ischemia/reperfusion-induced liver injury in rats. Thromb Haemost 88(3):473-480

33. Huguet C, Gavelli A, Chieco PA, Bona S, Harb J, Joseph JM, Jobard J, Gramaglia M, Lasserre M (1992) Liver ischemia for hepatic resection: where is the limit? Surgery 111(3):251-259 